\title{
Systematic Review \\ The Effects of Different Invitation Schemes on the Use of Fecal Occult Blood Tests for Colorectal Cancer Screening: Systematic Review of Randomized Controlled Trials
}

\author{
Laura F. Gruner ${ }^{1,2}{ }^{(D}$, Efrat L. Amitay ${ }^{1}$, Thomas Heisser ${ }^{1,2}$, Feng Guo ${ }^{1}$, Tobias Niedermaier ${ }^{1}\left(\mathbb{D}\right.$, Anton Gies $^{3}(\mathbb{D}$, \\ Michael Hoffmeister ${ }^{1}$ (D) and Hermann Brenner $1,3,4, * \mathbb{D}$
}

1 German Cancer Research Center (DKFZ), Division of Clinical Epidemiology and Aging Research, 69120 Heidelberg, Germany; l.gruner@dkfz.de (L.F.G.); e.amitay@dkfz-heidelberg.de (E.L.A.); t.heisser@dkfz-heidelberg.de (T.H.); f.guo@dkfz-heidelberg.de (F.G.); t.niedermaier@dkfz-heidelberg.de (T.N.); m.hoffmeister@dkfz-heidelberg.de (M.H.)

2 Medical Faculty Heidelberg, Heidelberg University, 69120 Heidelberg, Germany

3 Division of Preventive Oncology, German Cancer Research Center (DKFZ) and National Center for Tumor Diseases (NCT), 69120 Heidelberg, Germany; anton.gies@nct-heidelberg.de

4 German Cancer Consortium (DKTK), German Cancer Research Center (DKFZ), 69120 Heidelberg, Germany

* Correspondence: h.brenner@dkfz.de; Tel.: +49-6221-421300; Fax: +49-6221-4213002

\section{check for} updates

Citation: Gruner, L.F.; Amitay, E.L.; Heisser, T.; Guo, F.; Niedermaier, T.; Gies, A.; Hoffmeister, M.; Brenner, H. The Effects of Different Invitation Schemes on the Use of Fecal Occult Blood Tests for Colorectal Cancer Screening: Systematic Review of Randomized Controlled Trials. Cancers 2021, 13, 1520. https:// doi.org/10.3390/cancers13071520

Academic Editor: Jennifer Black

Received: 4 March 2021

Accepted: 22 March 2021

Published: 25 March 2021

Publisher's Note: MDPI stays neutral with regard to jurisdictional claims in published maps and institutional affiliations.

Copyright: (C) 2021 by the authors. Licensee MDPI, Basel, Switzerland. This article is an open access article distributed under the terms and conditions of the Creative Commons Attribution (CC BY) license (https:/ / creativecommons.org/licenses/by/ $4.0 /)$.
Simple Summary: There is large heterogeneity in invitation schemes and participation rates in colorectal cancer screening programs offering fecal occult blood tests (nowadays mostly fecal immunochemical tests). It is unclear what the most effective invitation strategies are for fecal occult blood tests. In this systematic review, advance notification, mailed fecal occult blood test, and reminders had major, consistent, and complementary potential to increase participation in fecal occult blood test-based colorectal cancer screening. Our findings show that the effectiveness of invitations for fecal occult blood test-based colorectal cancer screening can be substantially increased across several settings by the implementation of comprehensive invitation strategies.

\begin{abstract}
Personal invitations for fecal occult blood tests (nowadays mostly fecal immunochemical tests) are increasingly used to raise their usage for colorectal cancer screening. However, there is a large heterogeneity in applied invitation schemes. We aimed to review evidence for the effectiveness of various invitation schemes. The main outcome was the fecal occult blood test usage rate. A systematic search was performed in Medline and Web of Science (up to 9 July 2020). Randomized controlled trials or cluster-randomized controlled trials were eligible, which reported on general invitations for fecal occult blood test-based colorectal cancer screening sent to the general population at average colorectal cancer risk. (PROSPERO 2020 CRD42020169409). Overall, 34 studies were included. Invitations with an attached, i.e., mailed fecal occult blood test consistently increased test usage by $4-19.7 \%$ points, compared to other methods of test provision. Likewise, the introduction of advance notification consistently led to a higher usage rate, with an increase of $3.3-10.8 \%$ points. Reminders showed positive but varying effects by method. With an increase of $8.5-15.8 \%$ points, letter or email reminders were more effective than reminders by phone call or text message $(0.6-6.5 \%$ points). Inconsistent results were found for financial incentives ((-8.4)-20\% points) and for added or changed invitation material ((-3.5)-11.8\% points). With $3.5-24.7 \%$ points, the strongest increases in use were achieved by multifaceted invitation, implementing multiple components. Any invitation scheme was superior over no invitation. Advance notification, mailing of fecal occult blood test, and reminders were consistently shown to have major, complementary potential to increase participation in fecal occult blood test-based colorectal cancer screening settings.
\end{abstract}

Keywords: colorectal cancer; early detection; screening; fecal occult blood tests; invitation 


\section{Introduction}

Colorectal cancer (CRC) is the third most common cancer globally, accounting for approximately 1.8 million new cancer cases and 900,000 cancer-related deaths per year [1]. Screening with fecal occult blood tests, i.e., guaiac-based fecal occult blood tests (gFOBTs) or fecal immunochemical tests (FITs), and endoscopic methods have been shown by randomized, observational, and modeling studies to effectively reduce CRC incidence and mortality [2-4]. For gFOBTs, randomized clinical trials showed a reduction in CRC-related mortality by up to $30 \%$ with regular annual or biennial usage [3]. Thus, many European countries have implemented fecal occult blood test-based population-wide screening programs, and the majority of them have meanwhile switched from the long-established gFOBTs to FITs, [5] which have a substantially higher sensitivity for the detection of CRC and its precursors $[6,7]$.

Still, participation rates are often low, especially where gFOBTs/FITs are offered in opportunistic screening programs (i.e., without targeted invitations of the population entitled to screening) [5]. An increasing number of differing schemes have been introduced to invite the entitled population to gFOBT/FIT screenings in organized screening programs, using different approaches to enhance adherence, such as different methods of gFOBT/FIT provision (e.g., by mail or low-threshold pick up), advance notification, or reminder systems, among others.

In order to inform decisions regarding design elements of screening programs, we aimed to provide a systematic review of the evidence on effectiveness of various invitation measures to enhance adherence to gFOBT/FIT-based screening, from randomized and cluster-randomized controlled trials that were conducted in the general population at average CRC risk.

\section{Methods}

\subsection{Data Sources and Searches}

This systematic review was performed according to the PRISMA guidelines [8] (PROSPERO 2020 CRD42020169409).

The literature was searched systematically on January 23, 2020 (repeated on 9 July 2020) in Medline (legacy PubMed) and Web of Science using keywords and MeSH terms but no restrictions for language or date. Additionally, reference lists of included papers and of relevant previous systematic reviews, identified by the search strategy, were searched. The specific search terms are provided in the Supplementary Materials. Duplicates were removed, and titles and abstracts were screened for relevant articles. Selection of articles based on pre-defined eligibility criteria was performed by two authors (L.F.G., E.L.A.).

\subsection{Study Selection}

Eligible studies included randomized or cluster-randomized controlled trials investigating invitation schemes for gFOBT/FIT-based CRC screening in the general population with average CRC risk (without specific focus, e.g., on study volunteers or previous screening users only). Other interventions to enhance CRC screening were not included (e.g., personal navigator). The main outcome was gFOBT/FIT usage rate achieved in different invitation schemes in the general population, indicated by the difference in \%-points to a reference group within a certain pre-defined time period (i.e., follow-up after invitation).

\subsection{Data Extraction and Quality Assessment}

Predefined forms were used for data extraction, which was performed independently by L.F.G. and E.L.A. Detailed data on applied invitation schemes were collected. Additionally, L.F.G. and E.L.A. individually assessed study quality (on study level) using the revised Cochrane risk-of-bias tool for randomized trials (RoB 2), which allowed the assessment of the risk of bias in five distinct domains (randomization process, deviations from intended interventions, missing outcome data, measurement of the outcome, and selection of the reported result) [9]. The extracted data were compared between authors and disagreements were solved by discussion. 


\subsection{Data Synthesis}

Results of eligible studies were displayed in overview tables and figures. Meta-analyses were not performed due to the large heterogeneity between invitation schemes in the included studies.

\section{Results}

\subsection{Study Selection}

The systematic search identified 2353 records, 643 of which were duplicates (Figure 1, PRISMA flow diagram). Title and abstract screening was performed and 1635 of 1710 records were not eligible and excluded. 75 full-texts were assessed for eligibility according to pre-specified criteria: 42 were excluded (no general gFOBT/FIT invitation in the general population, $n=22$; observational study, $n=13$; comparison of modalities (e.g., FIT, gFOBT, or sigmoidoscopy), $n=5$; self-reported outcome, $n=1$; or population included in another trial, $n=1$ ). One additional study was identified by cross-referencing. Thus, the systematic review comprises 34 studies [10-43].
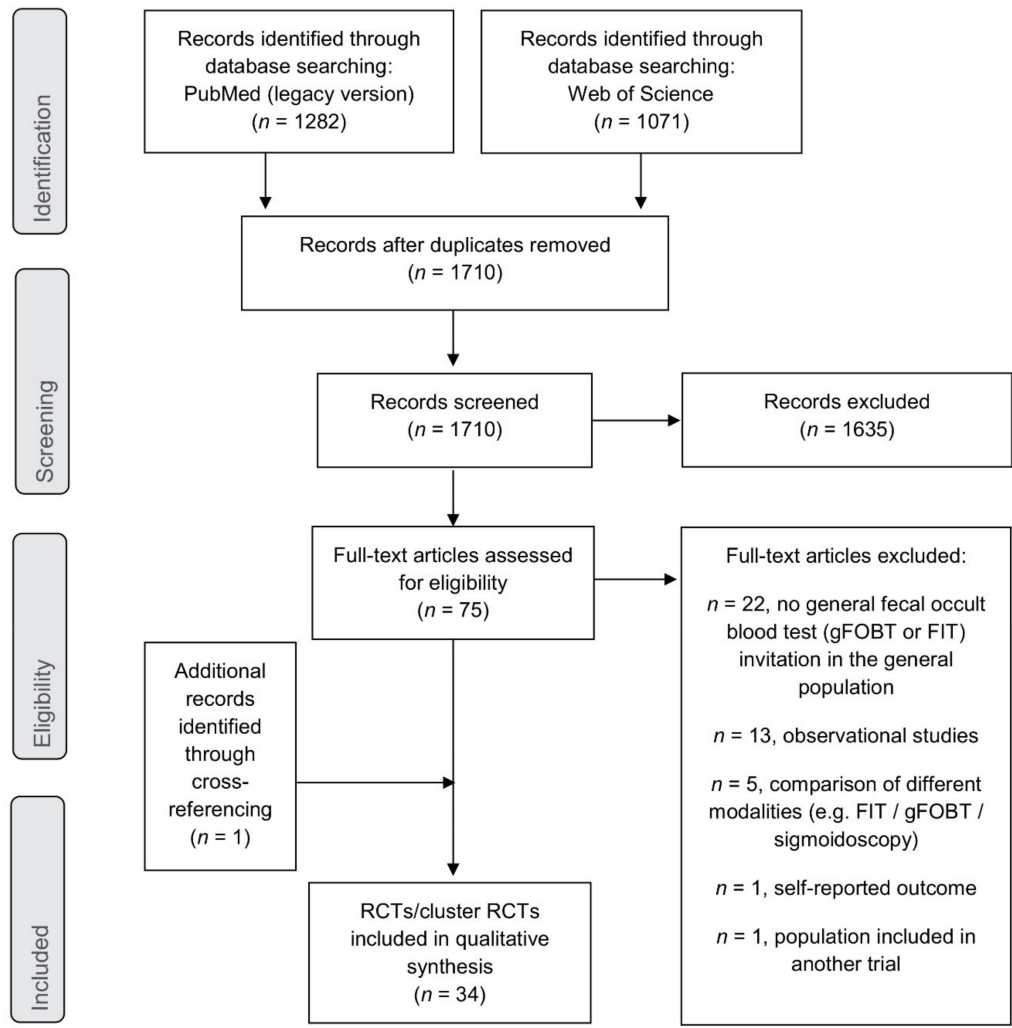

Figure 1. PRISMA flow diagram. $C R C=$ colorectal cancer; $F I T=$ fecal immunochemical test; gFOBT = guaiac-based fecal occult blood test; RCT = randomized controlled trial .

\subsection{Study Characteristics}

The included studies were from 11 countries (14 from the USA, 6 from England, 3 from Israel, 2 from Germany, 2 from the Netherlands, 2 from Scotland, 1 from Australia, 1 from France, 1 from Italy, 1 from Portugal, and 1 from Spain), and were published between 1991 and 2020 (Table 1). Sample size ranged between 202 and 150,417, and the targeted age groups between 45 and 80 years. All reported results for one round of invitation, and follow-up of gFOBT/FIT usage ranged between 3 and 12 months. 16 studies used gFOBT, 16 used FIT, and two did not specify. 
Table 1. Characteristics of randomized and cluster-randomized studies included in systematic review.

\begin{tabular}{|c|c|c|c|c|c|c|c|}
\hline & First Author/Year/Country & Age Range & $\begin{array}{l}\text { N Sample } \\
\text { (\% Females) }\end{array}$ & Setting & $\begin{array}{c}\text { Sender or Send on } \\
\text { Behalf of }\end{array}$ & $\begin{array}{l}\text { gFOBT or FIT } \\
\text { (Brand) }\end{array}$ & $\begin{array}{l}\text { F-Up After } \\
\text { Invitation }\end{array}$ \\
\hline & \multicolumn{7}{|c|}{ Population-Based Studies (National Screening Programs) } \\
\hline 1 & Hewitson/ 2011/ England [10] & $60-75$ & $1288(52.6 \%)$ & NSP & screening hubs & $\operatorname{gFOBT}(/)$ & 20 wk \\
\hline 2 & Libby/2011/ Scotland [11] & $50-74$ & $59,953(51.3 \%)$ & NSP & bowel screening center & $\operatorname{gFOBT}(/)$ & $26-32 \mathrm{wk}$ \\
\hline 3 & Lo/ 2014/ England [12], & $60-69$ & $23,182(/)$ & NSP & screening hubs & $\operatorname{gFOBT}(/)$ & / \\
\hline 4 & Barthe/ 2015/ France [13], & $50-74$ & $3422(56.7 \%)$ & NSP & district screening org & $\operatorname{gFOBT}(/)$ & $6 \mathrm{mo}$ \\
\hline 5 & O'Carroll/ 2015/ Scotland [14] & $50-74$ & $59,366(51 \%)$ & NSP & mail company & $\operatorname{gFOBT}(/)$ & $6 \mathrm{mo}$ \\
\hline 6 & Senore/ 2015/ Italy [15] & $50-69$ & $20,701(53.2 \%)$ & NSP & screening org & $\operatorname{FIT}(/)$ & $3 \mathrm{mo}$ \\
\hline 7 & Hagoel/ 2016/ Israel [16] & $50-74$ & $48,091(51 \%)$ & NSP & nat prog health services & / & $6 \mathrm{mo}$ \\
\hline 8 & McGregor/ 2016/ England [17], & $59-74$ & $150,417(51.2 \%)$ & NSP & screening hubs & $\operatorname{gFOBT}(/)$ & $18 \mathrm{wk}$ \\
\hline 9 & Hirst/ 2017/ England [18] & $60-74$ & $8269(52 \%)$ & NSP & mobile health org & gFOBT $(/)$ & $18 \mathrm{wk}$ \\
\hline 10 & Selva/ 2019/ Spain [19] & $50-69$ & $492(54.7 \%)$ & NSP & regional staff & $\operatorname{FIT}(/)$ & $6 \mathrm{mo}$ \\
\hline \multicolumn{8}{|c|}{ Population-Based Studies (Other) } \\
\hline 11 & Myers / 1991/ USA [20] & $50-74$ & $2201(47 \%)$ & $\mathrm{HMO}$ & central screening office & gFOBT (HemaWipe) & $90 \mathrm{~d}$ \\
\hline 12 & Ore/ 2001/ Israel [21] & $50-74$ & $1940(50.2 \%)$ & $\mathrm{HMO}$ & / & gFOBT (Haemoccult II S) & $4 \mathrm{mo}$ \\
\hline 13 & Cole/ 2007/ Australia [22] & $50-74$ & $2400(/)$ & comm prog & central screening facility & FIT (InSures) & $12 \mathrm{wk}$ \\
\hline 14 & Muller / 2009/ USA [23] & $50-80$ & $1397(/)$ & HMO & researchers & $\operatorname{gFOBT}(/)$ & $3 \mathrm{mo}$ \\
\hline 16 & Van Roon/ 2011/ Netherlands [25] & $50-74$ & $4784(50.9 \%)$ & one region & / & FIT (OC Sensor) & / \\
\hline 17 & Denters / 2013/ Netherlands [26] & $50-75$ & $10,265(51 \%)$ & pilot prog & regional center & FIT (OC Sensor) & / \\
\hline 18 & Hoffmeister / 2017/ Germany [27] & 50 & $18,560(/)$ & one region & education minister & $\operatorname{gFOBT}(/)$ & $1 \mathrm{y}$ \\
\hline 19 & Gruner/2020/ Germany [28] & $50-54$ & $17,532(46.3 \%)$ & HMO & $\mathrm{HMO}$ & FIT (OC Sensor) & $1 \mathrm{y}$ \\
\hline \multicolumn{8}{|c|}{ Primary Care-Based Studies } \\
\hline 20 & Mant/ 1992/ England [29] & $45-64$ & $1588(47.9 \%)$ & PC practice & general practice & gFOBT (Haemoccult) & / \\
\hline 21 & Hart/ 1997/ England [30] & $61-70$ & $1571(52.8 \%)$ & PC practice & signed by senior partner & gFOBT (Haemoccult) & / \\
\hline 22 & Vinker / 2002/ Israel [31] & $50-75$ & $2315(52.2 \%)$ & PC clinics & / 1 & 1 & $1 \mathrm{y}$ \\
\hline 23 & Mehta/ 2018/ USA [32] & $50-74$ & $314(53.2 \%)$ & PC university clinic & researchers & FIT (OC Sensor) & $3 \mathrm{mo}$ \\
\hline 24 & Coronado/ 2019/ USA [33] & $50-74$ & $1767(56.9 \%)$ & comm health center & health center & FIT (InSure) & $6 \mathrm{mo}$ \\
\hline 25 & Mehta/ 2019/ USA [34] & $50-75$ & $897(56 \%)$ & PC university clinic & PC clinician & $\operatorname{FIT}(/)$ & $6 \mathrm{mo}$ \\
\hline 26 & Nisa/ 2019/ Portugal [35] & $50-74$ & $1652(51 \%)$ & public health center & head physician & $\operatorname{gFOBT}(/)$ & / \\
\hline
\end{tabular}


Table 1. Cont.

\begin{tabular}{|c|c|c|c|c|c|c|c|}
\hline & First Author/Year/Country & Age Range & $\begin{array}{l}N \text { Sample } \\
\text { (\% Females) }\end{array}$ & Setting & $\begin{array}{c}\text { Sender or Send on } \\
\text { Behalf of }\end{array}$ & $\begin{array}{c}\text { gFOBT or FIT } \\
\text { (Brand) }\end{array}$ & $\begin{array}{l}\text { F-Up After } \\
\text { Invitation }\end{array}$ \\
\hline \multicolumn{8}{|c|}{ Studies from Safety Net, FQHC, and Medicaid Settings } \\
\hline 27 & Jean-Jacques / 2012/ USA [36] & $50-80$ & $202(61.8 \%)$ & FQHC & medical professional & gFOBT (Hemoccult II S) & $4 \mathrm{mo}$ \\
\hline 28 & Hendren/ 2014/ USA [37] & $50-74$ & $240(/)$ & Safety net & outreach worker & $\operatorname{FIT}(/)$ & $1 \mathrm{y}$ \\
\hline 29 & Goldman/ 2015/ USA [38] & $50-74$ & $420(66 \%)$ & FQHC & health center network & FIT (OC Light) & $6 \mathrm{mo}$ \\
\hline 30 & Gupta/2016/ USA [39] & $50-64$ & $8565(61.8 \%)$ & Safety net & safety net health system & FIT (OC Sensor) & $6 \mathrm{mo}$ \\
\hline 31 & Brenner/ 2018/ USA [40] & $52-64$ & $1490(51.7 \%)$ & Medicaid & health department & FIT (OC Light) & $12 \mathrm{mo}$ \\
\hline 32 & Coronado/ 2018/ USA [41], & $50-74$ & $41,193(55.8 \%)$ & FQHC & clinic staff & $\operatorname{FIT}(/)$ & $12 \mathrm{mo}$ \\
\hline 33 & Mehta/ 2020/ USA [42] & $50-74$ & $281(63 \%)$ & FQHC & clinic sms platform & FIT & $3 \mathrm{mo}$ \\
\hline 34 & Somsouk/ 2020/ USA [43] & $50-75$ & $10,820(47.1 \%)$ & Safety net & study team & FIT (OC Light / Sensor) & $1 \mathrm{y}$ \\
\hline
\end{tabular}

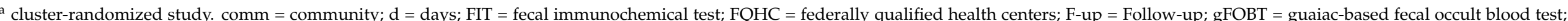

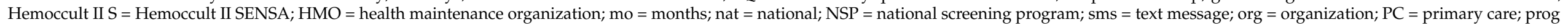
= program; $\mathrm{wk}=$ weeks; $\mathrm{y}=$ year $; /$ = not available. 


\subsection{Quality Assessment}

Quality assessment with the RoB 2 tool resulted in a low risk of bias for 14 studies $[10,11,13,14,16,19,26,28,32,34,38-40,42], 19$ studies with some concerns $[12,15,17,18,20-25,27,29-31,33,36,37,41,43]$, and one [35] at high risk of bias (Table S1). Concerns were mainly due to the ambiguity of randomization and baseline characteristics (domain 1 "randomization process"), and a lack of pre-specified protocol or analysis plan (domain 5 "selection of the reported result").

\section{Study Settings and Populations}

Most studies were from population-based settings $(n=19)$ (Table 1$)$, where service organizations mainly sent the invitations. Ten were performed in national screening programs [10-19], and nine in other population-based settings (e.g., within a specific region or health maintenance organization) [20-28]. Primary care settings $(n=7)$ included practices [29,30], clinics [31], university clinics [32,34], or health centers [33,35], and most invitations were sent on behalf of the physicians. Eight studies (all from the USA) included predominantly low-income or uninsured individuals in safety net $[37,39,43]$, federally qualified health centers (FQHC) [36,38,41,42], and Medicaid settings [40]. Primarily, the health system sent the invitation. In most studies, no invitation was sent to individuals with recent screening activities, e.g., gFOBT/FIT in the past year, endoscopic screening within up to 10 years $[13,16,19,23-26,28,32,34-43]$, or (family-) history of CRC or other severe medical issues $[10,15,16,19,23-25,28,29,32-34,36-43]$. Main results are presented by different intervention approaches in Figures 2 and 3, and by different settings in Tables S2-S5.

\subsection{Effect of Different gFOBT/FIT Access}

Provision of gFOBT/FIT can be categorized into directly mailed, sent upon request, or available for pick up, e.g., from the general practitioner (GP). Different access methods were investigated in three population-based studies $[21,27,28]$, two from primary care [29,32], and one among Medicaid beneficiaries [40] (Figure 2; Tables S3-S5). In all respective studies, invitation schemes with mailed gFOBT /FIT consistently resulted in the highest usage. When compared to pick up options, mailed gFOBT/FIT increased usage in one study from England by $11.1 \%$ points for gFOBT [29], and in two studies from Germany by $10 \%$ points for gFOBT [27] and $19.7 \%$ points for FITs [28]. However, request options (by reply mail, fax, email, or online form) led to an almost equivalent increase of $17.7 \%$ points in the latter study [28]. While Ore et al. [21] also reported almost equivalent effects of a request card and mailed gFOBT [21], an invitation letter with the option to opt-out of mailed FIT was superior over opt-in by almost $20 \%$ points [32]. One study conducted in the US Medicaid setting [40] observed higher usage (by $8.8 \%$ points) upon reminders with mailed FIT as compared to reminders with a request option.

\subsection{Effect of Advance Notification}

Advance notification was investigated in five population-based studies [11,15,19,22,25] (Tables S2 and S3), and consistently resulted in increased usage (Figure 2). Selva et al. [19] found an increase of $10.8 \%$ points by calling participants in advance to the standard national invitation procedure. The other four studies used letters to announce the upcoming invitation and observed increases in gFOBT/FIT usage rates between 3.3\% points and $8.8 \%$ points $[11,15,22,25]$. 


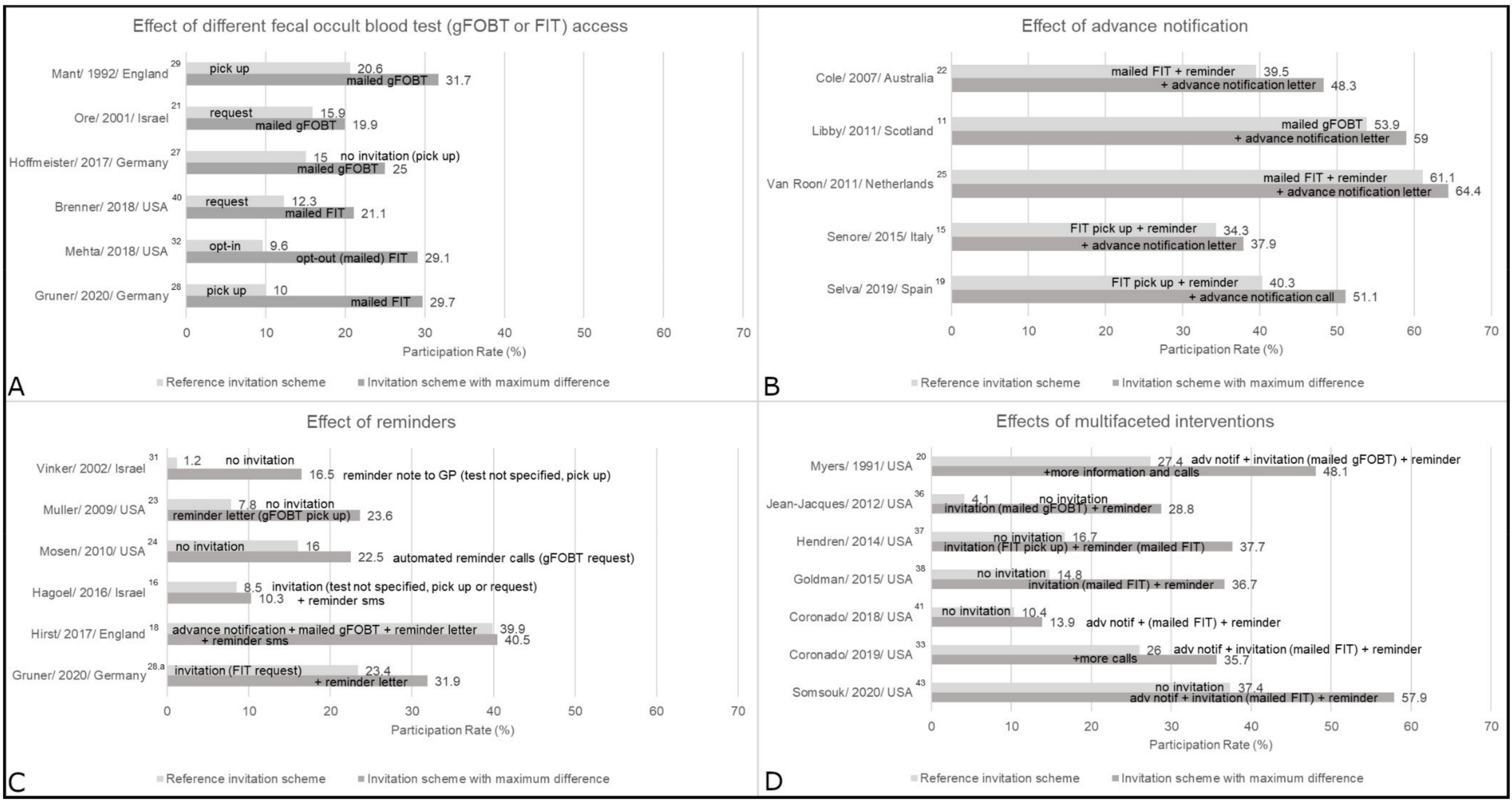

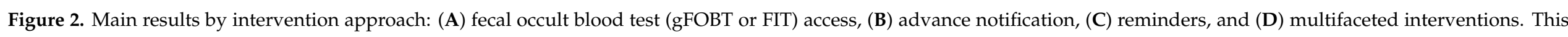

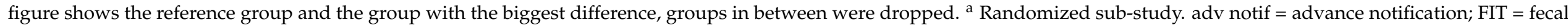
immunochemical test; gFOBT = guaiac-based fecal occult blood test; GP = general practitioner; sms = text message. 


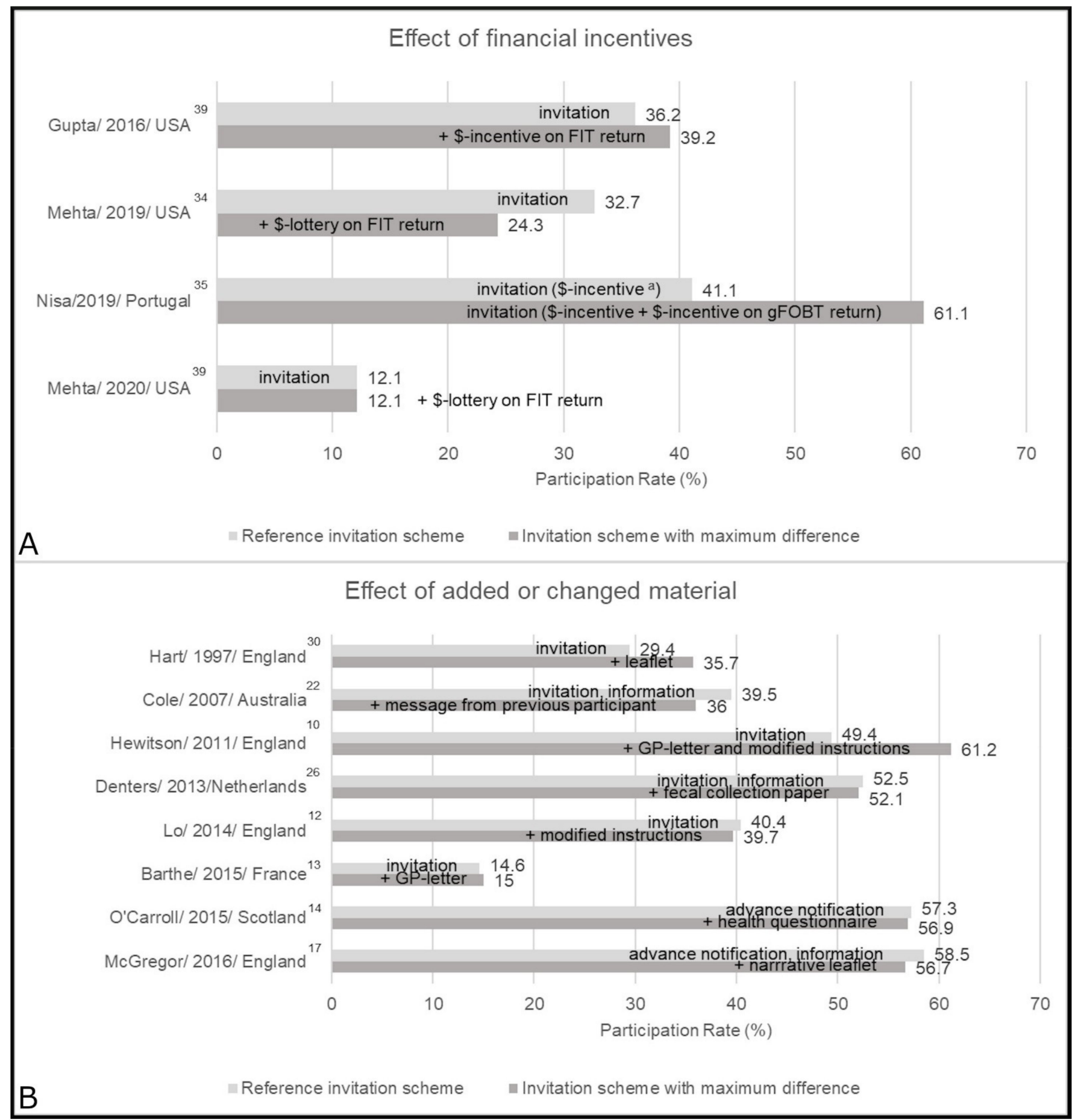

Figure 3. Main results by intervention approach: (A) financial incentives, and (B) added or changed material. This figure shows the reference group and the group with the biggest difference, groups in between were dropped ${ }^{\mathrm{a}}$. The sum of the divided incentive equals the once only incentive. FIT = fecal immunochemical test; gFOBT = guaiac-based fecal occult blood test; GP = general practitioner; \$ = financial.

\subsection{Effect of Reminders}

Five population-based studies $[16,18,23,24,28]$ and one primary care study [31] (Tables S2-S4) investigated reminders. Three did not specify any previous invitations $[23,24,31]$. All observed positive, albeit variable effects by method (Figure 2). In national screening programs in England and Israel, different text message reminders led to marginal increases in gFOBT /FIT usage by $0.6 \%$ points [18] and $0.7-1.8 \%$ points, respectively [16]. Auto- 
mated reminder calls with a request option increased usage by 6.5\% points in an American study [24]. In a randomized sub-study [28], reminder letters increased usage by $7.5-8.5 \%$ points. Muller et al. [23] used reminder letters and emails, which both were effective and increased usage of any CRC screening (including gFOBT) by $15.8 \%$ points and $14.9 \%$ points, respectively. Vinker et al. [31] provided data on a reminder note from the GP, or a letter or call addressed to the invitee, compared to usual care without invitation. The increase in usage rates was 15.3 and $10.7 \%$ points, respectively.

\subsection{Effect of Financial Incentives}

The effects of financial incentives were mixed in primary care [34,35], safety net [39], and FQHC settings [42] (Figure 3; Tables S4-S5). Three studies [34,39,42] concluded that different financial incentives (around \$5-10 or chance of winning \$100) did not increase FIT usage rate. In a study by Nisa et al. [35] (at high risk of bias) a divided incentive (5€ attached, and $5 €$ upon gFOBT usage) yielded a $20 \%$ points higher usage rate as compared to one attached incentive of $10 €$.

\subsection{Effect of Added or Changed Material}

The effects of added or changed material (e.g., enhanced leaflets, or GP signature) were mixed in seven population-based studies $[10,12-14,17,22,26]$ and one from primary care [30] (Figure 3; Tables S2-S4). A letter from the GP did not show an effect in one study [13], but increased usage by $11.8 \%$ points in combination with enhanced instructions [10]. In 1997, Hart et al. [30] observed positive effects of an additional information leaflet, while the addition of a second leaflet [17] or modified instructions [12] resulted in minor negative changes in the more recent British national screening program. In Australia, specific messages on risk or from previous participants led to changes of $0.8 \%$ points and $-3.5 \%$ points, respectively [22]. Health questionnaires [14] or provision of fecal collection paper [26] showed no effect.

\subsection{Effects of Multifaceted Interventions}

Multifaceted invitations, i.e., simultaneous implementation of several interventions, were investigated in population-based [20], primary care [33], and safety net or FQHC settings [36-38,41,43] (Figure 2; Tables S3-S5). Combinations of advance notification, mailed gFOBT/FIT, and reminders were investigated by two studies [20,33], with the most comprehensive approaches leading to the most pronounced increases, by $20.7 \%$ points and $9.7 \%$ points, respectively. In the safety net and $\mathrm{FQHC}$ studies, multifaceted invitations were compared against usual care without any invitation, and all [36-38,43] but one [41] observed an increase of $>20 \%$ points.

\subsection{Usage Rates without Invitation}

Without invitation (i.e., opportunistic use of screening), usage rates were between 1 and $17 \%$ [23,24,27,31,36-38,41] (Tables S3-S5). One study [43] with higher rates used medical assistants and additional software in usual care. In the respective studies, any personal invitation yielded increased gFOBT/FIT usage rates.

\section{Discussion}

The aim of this systematic review was to summarize studies that investigated the effects of different invitation schemes for gFOBTs/FITs on their utilization in the general population. Consistently, mailed gFOBT/FIT, advance notification, and reminders increased usage rates. An increase of $4-19.7 \%$ points was achieved for mailed gFOBT/FIT, while the implementation of advance notification increased usage by $3.3-10.8 \%$ points. Reminders showed positive but varying effects by method. With an increase of $8.5-15.8 \%$ points, letter or email reminders were more effective than reminders by phone call or text message (maximum change of $0.6-6.5 \%$ points). Findings on the effects of financial incentives were inconsistent (maximum change of $(-8.4)-20 \%$ points), and though results for 
added or changed invitation material were also mixed (maximum change of (-3.5)-11.8\% points), enhanced instructions and a GP-endorsement letter increased gFOBT usage by up to $12 \%$ points. Studies in which several interventions were implemented at the same time (multifaceted invitation) all reported higher gFOBT/FIT usage rates than controls, with an increase in the range of 3.5 to $24.7 \%$ points. Any invitation scheme was superior over no invitation.

To our knowledge, this is the first systematic review of randomized and clusterrandomized trials to provide comprehensive details on individual design aspects and the effectiveness of general invitations for gFOBT/FIT addressed at the general population. It is different from five previous systematic reviews, which summarized data on how to increase gFOBT /FIT usage, but included all kinds of interventions (in addition to general invitations) and outcomes [44-46], had a specific focus on mailed outreach $[47,48]$ or on FITs [44], or also reviewed non-randomized studies [44,47,48]. Although these reviews also included studies on different invitation schemes, many of these were not addressed at the general population but at specific groups, such as study volunteers or previous test users only [44-48], which potentially limits direct comparison and transferability to routine practice.

Previous reviews by Rat et al. [45] and by Issaka et al. [44], which described any interventions to increase usage of gFOBTs/FITs, reported positive effects for mailed gFOBTs/FITs, advance notification, and reminders. Furthermore, calls from personal advisors [45] or FITs offered in combination with vaccinations [44] were other non-invitation interventions that showed the potential to increase FOBT usage.

The majority of population-based CRC screening programs in the European Union have meanwhile implemented the concept of invitation letters with attached gFOBT/FIT, which are sent out by screening hubs [49]. Nevertheless, there are countries, such as Germany, where FITs remain to be picked up at doctors' offices and usage rates have remained very low, which suggests room for major improvement. The second European screening report indicates that these programs are publicly funded and that health insurance plans act as funding sources in more than half of these programs [50]. At 49.5\% (range: 22.8-71.3\%), overall participation was higher in countries with FIT-based approaches than in those that used the gFOBT (overall usage at 33.2\%, range: $4.5-66.6 \%$ ) [51]. Thus, it is possible that the invitation schemes presented in this systematic review, which used gFOBT, would have achieved even higher response rates by using the FIT.

According to EU Guidelines, the desirable usage rate of CRC screening is $>65 \%$ [51]. In the current review, one Dutch population-based study reported FIT usage rates close to this recommendation at $64.4 \%$ [25]. In this invitation scheme an advance notification letter with information was sent. Two weeks later, individuals received an invitation letter, which included an information brochure, an FIT, an instruction leaflet for sample taking, an informed consent form, and a postpaid reply envelope. Those who did not return the FIT within six weeks received a reminder letter [25]. A comparable approach was studied in a Dutch population-based study [52], and several rounds of biannual invitations were well accepted, with cumulative usage rates of $>70 \%$ [53,54]. Additionally, the first five years of the Dutch national screening program (including advance notification one week prior to an invitation letter with an FIT (postpaid return), followed by a reminder letter) [55] also showed usage rates $>70 \%$ [55-59].

Access to gFOBT/FIT through direct mailing was shown to be more effective than other methods for providing access within six studies investigating this aspect, and, moreover, was the most commonly used access method across all included studies. Yet, it is also likely to be the most expensive way to provide gFOBTs/FITs and to create the highest number of unused tests. To date, few trials have investigated the effect of request options for gFOBTs/FITs, which request only a small additional effort from the individual as compared to directly mailed tests, but might save economic and environmental costs. In this systematic review, promising results were found in population-based settings, where usage rates of requested gFOBTs/FITs were almost comparable to mailed tests [21,28]. 
The acceptance of request options for more user-friendly FITs [28] was higher than for gFOBTs [21], which is in line with previous experiences [51,60]. If, and to what extent, the provision of gFOBTs/FITs upon easy access is cost-effective should thus be addressed by further comprehensive health economical evaluations. It might additionally be relevant to offer postpaid return of the used gFOBTs/FITs to avoid barriers such as having to take the test to the GP or paying for postage. Although in this systematic review the results for GP-involvement were mixed, more than half of the studies conducted in the primary care setting already included a primary care physician or clinician in the invitation process (e.g., GP-signature by default) which might have contributed to the respective usage. Furthermore, the effectiveness of the different invitation schemes in sub-groups of the target population (such as gender, age, and socioeconomic status) was not consistently reported in the included studies, and should be investigated more in future research.

Specific strengths of this systematic review include a detailed description of gFOBT/FIT invitation schemes in the general, screening-eligible population, which were investigated in randomized or cluster-randomized controlled trials. It complements previous systematic reviews [13] with new studies on the specific effects of gFOBT/FIT provision in the frame of invitations, while studies with focus on specific groups or other interventions were excluded to enhance comparability to routine invitation practice. Nevertheless, this systematic review has several limitations. Characteristics (including settings, populations, and sample size, but also sender of the invitation, follow-up duration, and specific procedures) varied greatly among the included studies, therefore limiting direct comparability of the results. Furthermore, invitation procedures were described according to the used terminology in the respective publications, and although some studies stated to investigate a reminder $[23,24,31,40]$, it was the first described contact and might thus be comparable to an initial invitation. Studies on multifaceted interventions were all performed in the USA, however, it can be assumed that comprehensive invitation models are effective in other countries as well, where more specific design aspects were investigated. Due to the large heterogeneity between studies, no quantitative measurement of comparison for the most effective invitation scheme was made. However, it can be assumed from the summarized data that a comprehensive invitation strategy including several contact attempts combined with low-threshold access to gFOBT/FIT (e.g., a combination of advanced notification, mailed gFOBT/FIT, and a reminder) has the strong potential to increase usage.

Some of the frequently observed risks of bias, such as missing pre-specified analysis plans, possibly did not influence the outcome gFOBT/FIT usage, which was either yes or no. Furthermore, it is likely that in most trials without informed consent, the target population did not even know that they were included in a study, and were therefore completely blinded.

In conclusion, this systematic review summarizes findings from controlled trials on CRC screening invitations, in which mailed gFOBT/FIT, advance notification, and reminders consistently show the potential for high test usage across various settings. A synergistic effect for a substantial increase in CRC screening usage might be achievable by combining various interventions. Low-barrier provision upon request appears to be an almost equally effective alternative to direct mailing of gFOBT/FIT, and could have major economical and environmental advantages in population-wide screening programs.

Supplementary Materials: The following are available online at https: / www.mdpi.com/article / 10.3390 / cancers13071520/s1. Supplementary Materials. Online database search strategy, PubMed (legacy version); Table S1. Risk of bias assessment of randomized and cluster-randomized studies included in systematic review (Tool:RoB 2); Table S2. Invitation characteristics and gFOBT/FIT usage rates among population-based randomized and cluster-randomized studies performed within a national screening program; Table S3. Invitation characteristics and gFOBT/FIT usage rates among other population-based randomized studies; Table S4. Invitation characteristics and gFOBT/FIT usage rates among primary care-based randomized studies; Table S5. Invitation characteristics and gFOBT/FIT usage rates among randomized and cluster-randomized studies from safety net, FQHC, and Medicaid settings. References [10-43] are cited in the Supplementary Materials. 
Author Contributions: H.B. designed the study. L.F.G. and E.L.A. conducted the literature search and extracted the data. L.F.G. conducted the synthesis and drafted the manuscript. E.L.A., T.H., F.G., T.N., A.G., M.H. and H.B. contributed important intellectual content and critically revised the manuscript. All authors have read and agreed to the published version of the manuscript.

Funding: This work was supported in part by a grant from AOK Baden-Wuerttemberg. The funding source played no role in the systematic review.

Institutional Review Board Statement: Not applicable.

Informed Consent Statement: Not applicable.

Data Availability Statement: Not applicable.

Conflicts of Interest: The work of L.F.G. was supported by a grant from AOK Baden-Wuerttemberg (the funding source had no role in the design, execution, interpretation, or writing of the systematic review). The other authors declare that there are no conflicts of interest.

\section{References}

1. Bray, F.; Ferlay, J.; Soerjomataram, I.; Siegel, R.L.; Torre, L.A.; Jemal, A. Global cancer statistics 2018: GLOBOCAN estimates of incidence and mortality worldwide for 36 cancers in 185 countries. CA Cancer J. Clin. 2018, 68, 394-424. [CrossRef] [PubMed]

2. Brenner, H.; Stock, C.; Hoffmeister, M. Effect of screening sigmoidoscopy and screening colonoscopy on colorectal cancer incidence and mortality: Systematic review and meta-analysis of randomised controlled trials and observational studies. BMJ 2014, 348, g2467. [CrossRef]

3. Shaukat, A.; Mongin, S.J.; Geisser, M.S.; Lederle, F.A.; Bond, J.H.; Mandel, J.S.; Church, T.R. Long-Term Mortality after Screening for Colorectal Cancer. N. Engl. J. Med. 2013, 369, 1106-1114. [CrossRef] [PubMed]

4. Buskermolen, M.; Cenin, D.R.; Helsingen, L.M.; Guyatt, G.; Vandvik, P.O.; Haug, U.; Bretthauer, M.; Lansdorp-Vogelaar, I. Colorectal cancer screening with faecal immunochemical testing, sigmoidoscopy or colonoscopy: A microsimulation modelling study. BMJ 2019, 367, 15383. [CrossRef]

5. Cardoso, R.; Guo, F.; Heisser, T.; Hoffmeister, M.; Brenner, H. Utilisation of Colorectal Cancer Screening Tests in European Countries by Type of Screening Offer: Results from the European Health Interview Survey. Cancers 2020, 12, 1409. [CrossRef] [PubMed]

6. Brenner, H.; Tao, S. Superior diagnostic performance of faecal immunochemical tests for haemoglobin in a head-to-head comparison with guaiac based faecal occult blood test among 2235 participants of screening colonoscopy. Eur. J. Cancer. 2013, 49, 3049-3054. [CrossRef] [PubMed]

7. Gies, A.; Bhardwaj, M.; Stock, C.; Schrotz-King, P.; Brenner, H. Quantitative fecal immunochemical tests for colorectal cancer screening. Int. J. Cancer. 2018, 143, 234-244. [CrossRef]

8. Moher, D.; Liberati, A.; Tetzlaff, J.; Altman, D.G.; PRISMA Group. Preferred reporting items for systematic reviews and meta-analyses: The PRISMA statement. Int. J. Surg. 2010, 8, 336-341. [CrossRef] [PubMed]

9. Sterne, J.A.C.; Savovic, J.; Page, M.J.; Elbers, R.G.; Blencowe, N.S.; Boutron, I.; Cates, C.J.; Cheng, H.Y.; Corbett, M.S.; Eldridge, S.M.; et al. RoB 2: A revised tool for assessing risk of bias in randomised trials. BMJ 2019, 366, 14898. [CrossRef]

10. Hewitson, P.; Ward, A.M.; Heneghan, C.; Halloran, S.P.; Mant, D. Primary care endorsement letter and a patient leaflet to improve participation in colorectal cancer screening: Results of a factorial randomised trial. Br. J. Cancer 2011, 105, 475-480. [CrossRef]

11. Libby, G.; Bray, J.; Champion, J.; Brownlee, L.A.; Birrell, J.; Gorman, D.R.; Crighton, E.M.; Fraser, C.G.; Steele, R.J.C. Prenotification increases uptake of colorectal cancer screening in all demographic groups: A randomized controlled trial. J. Med. Screen. 2011, 18, 24-29. [CrossRef] [PubMed]

12. Lo, S.H.; Good, A.; Sheeran, P.; Baio, G.; Rainbow, S.; Vart, G.; von Wagner, C.; Wardle, J. Preformulated Implementation Intentions to Promote Colorectal Cancer Screening: A Cluster-Randomized Trial. Health Psychol. 2014, 33, 998-1002. [CrossRef]

13. Barthe, J.; Perrodeau, E.; Gilberg, S.; Ravaud, P.; Ghasarossian, C.; Marchand-Buttin, F.; Deyra, J.; Falcoff, H. Impact of a Doctor's Invitation on Participation in Colorectal Cancer Screening: A Cluster Randomized Trial. Am. J. Med. 2015, 128, 1024-e1. [CrossRef]

14. O'Carroll, R.E.; Chambers, J.A.; Brownlee, L.; Libby, G.; Steele, R.J. Anticipated regret to increase uptake of colorectal cancer screening (ARTICS): A randomised controlled trial. Soc. Sci. Med. 2015, 142, 118-127. [CrossRef] [PubMed]

15. Senore, C.; Ederle, A.; DePretis, G.; Magnani, C.; Canuti, D.; Deandrea, S.; Zorzi, M.; Barca, A.; Bestagini, P.; Faitini, K.; et al. Invitation strategies for colorectal cancer screening programmes: The impact of an advance notification letter. Prev. Med. 2015, 73, 106-111. [CrossRef] [PubMed]

16. Hagoel, L.; Neter, E.; Stein, N.; Rennert, G. Harnessing the Question-Behavior Effect to Enhance Colorectal Cancer Screening in an mHealth Experiment. Am. J. Public Health 2016, 106, 1998-2004. [CrossRef]

17. McGregor, L.M.; von Wagner, C.; Atkin, W.; Kralj-Hans, I.; Halloran, S.P.; Handley, G.; Logan, R.F.; Rainbow, S.; Smith, S.; Snowball, J.; et al. Reducing the Social Gradient in Uptake of the NHS Colorectal Cancer Screening Programme Using a Narrative-Based Information Leaflet: A Cluster-Randomised Trial. Gastroenterol. Res. Pract. 2016, 2016, 3670150. [CrossRef] 
18. Hirst, Y.; Skrobanski, H.; Kerrison, R.S.; Kobayashi, L.C.; Counsell, N.; Djedovic, N.; Ruwende, J.; Stewart, M.; von Wagner, C. Textmessage Reminders in Colorectal Cancer Screening (TRICCS): A randomised controlled trial. Br. J. Cancer 2017, 116, 1408-1414. [CrossRef] [PubMed]

19. Selva, A.; Tora, N.; Pascual, E.; Espinas, J.A.; Bare, M. Effectiveness of a brief phone intervention to increase participation in a population-based colorectal cancer screening programme: A randomized controlled trial. Colorectal Dis. 2019, 21, 1120-1129. [CrossRef]

20. Myers, R.E.; Ross, E.A.; Wolf, T.A.; Balshem, A.; Jepson, C.; Millner, L. Behavioral interventions to increase adherence in colorectal cancer screening. Med. Care. 1991, 29, 1039-1050. [CrossRef]

21. Ore, L.; Hagoel, L.; Lavi, I.; Rennert, G. Screening with faecal occult blood test (FOBT) for colorectal cancer: Assessment of two methods that attempt to improve compliance. Eur. J. Cancer Prev. 2001, 10, 251-256. [CrossRef] [PubMed]

22. Cole, S.R.; Smith, A.; Wilson, C.; Turnbull, D.; Esterman, A.; Young, G.P. An advance notification letter increases participation in colorectal cancer screening. J. Med. Screen. 2007, 14, 73-75. [CrossRef] [PubMed]

23. Muller, D.; Logan, J.; Dorr, D.; Mosen, D. The effectiveness of a secure email reminder system for colorectal cancer screening. AMIA Аnпu Symp. Proc. 2009, 2009, 457-461.

24. Mosen, D.M.; Feldstein, A.C.; Perrin, N.; Rosales, A.G.; Smith, D.H.; Liles, E.G.; Schneider, J.L.; Lafata, J.E.; Myers, R.E.; Kositch, M.; et al. Automated Telephone Calls Improved Completion of Fecal Occult Blood Testing. Med. Care 2010, 48, 604-610. [CrossRef]

25. Van Roon, A.H.; Hol, L.; Wilschut, J.A.; Reijerink, J.C.; van Vuuren, A.J.; van Ballegooijen, M.; Habbema, J.D.; van Leerdam, M.E.; Kuipers, E.J. Advance notification letters increase adherence in colorectal cancer screening: A population-based randomized trial. Prev. Med. 2011, 52, 448-451. [CrossRef] [PubMed]

26. Denters, M.J.; Deutekom, M.; Bossuyt, P.M.; Fockens, P.; Dekker, E. A feces collection paper does not enhance participation in a fecal immunochemical test-based colorectal cancer screening program: Randomized clinical trial. Eur. J. Cancer Prev. 2013, 22, 299-304. [CrossRef] [PubMed]

27. Hoffmeister, M.; Holleczek, B.; Zwink, N.; Stock, C.; Stegmaier, C.; Brenner, H. Screening for Bowel Cancer: Increasing Participation via Personal Invitation. Dtsch. Ärzteblatt Int. 2017, 114, 87-93. [CrossRef]

28. Gruner, L.F.; Hoffmeister, M.; Ludwig, L.; Meny, S.; Brenner, H. The effects of differing invitation models on the uptake of immunological fecal occult blood testing-Results from a randomized controlled trial. Dtsch. Ärzteblatt Int. 2020, 117, 423-430. [CrossRef]

29. Mant, D.; Fuller, A.; Northover, J.; Astrop, P.; Chivers, A.; Crockett, A.; Clements, S.; Lawrence, M. Patient compliance with colorectal cancer screening in general practice. Br. J. Gen. Pract. 1992, 42, 18-20.

30. Hart, A.R.; Barone, T.L.; Gay, S.P.; Inglis, A.; Griffin, L.; Tallon, C.A.; Mayberry, J.F. The effect on compliance of a health education leaflet in colorectal cancer screening in general practice in central England. J. Epidemiol. Community Health 1997, 51, 187-191. [CrossRef] [PubMed]

31. Vinker, S.; Nakar, S.; Rosenberg, E.; Kitai, E. The role of family physcians in increasing annual fecal occult blood test screening coverage: A prospective intervention study. ISR Med. Assoc. J. 2002, 4, 424-425. [PubMed]

32. Mehta, S.J.; Khan, T.; Guerra, C.; Reitz, C.; McAuliffe, T.; Volpp, K.G.; Asch, D.A.; Doubeni, C.A. A Randomized Controlled Trial of Opt-in Versus Opt-Out Colorectal Cancer Screening Outreach. Am. J. Gastroenterol. 2018, 113, 1848-1854. [CrossRef]

33. Coronado, G.D.; Thompson, J.H.; Petrik, A.F.; Nyongesa, D.B.; Leo, M.C.; Castillo, M.; Younger, B.; Escaron, A.; Chen, A. Patient-Refined Messaging for a Mailed Colorectal Cancer Screening Program: Findings from the PROMPT Study. J. Am. Board Fam. Med. 2019, 32, 318-328. [CrossRef]

34. Mehta, S.J.; Pepe, R.S.; Gabler, N.B.; Kanneganti, M.; Reitz, C.; Saia, C.; Teel, J.; Asch, D.A.; Volpp, K.G.; Doubeni, C.A. Effect of Financial Incentives on Patient Use of Mailed Colorectal Cancer Screening Tests A Randomized Clinical Trial. JAMA Netw. Open 2019, 2, e191156. [CrossRef] [PubMed]

35. Nisa, C.F.; Belanger, J.J.; Schumpe, B.M. Parts greater than their sum: Randomized controlled trial testing partitioned incentives to increase cancer screening. Ann. N. Y. Acad. Sci. 2019, 1449, 46-55. [CrossRef]

36. Jean-Jacques, M.; Kaleba, E.O.; Gatta, J.L.; Gracia, G.; Ryan, E.R.; Choucair, B.N. Program to Improve Colorectal Cancer Screening in a Low-Income, Racially Diverse Population: A Randomized Controlled Trial. Ann. Fam. Med. 2012, 10, 412-417. [CrossRef] [PubMed]

37. Hendren, S.; Winters, P.; Humiston, S.; Idris, A.; Li, S.X.L.; Ford, P.; Specht, R.; Marcus, S.; Mendoza, M.; Fiscella, K. Randomized, Controlled Trial of a Multimodal Intervention to Improve Cancer Screening Rates in a Safety-Net Primary Care Practice. J. Gen. Intern. Med. 2014, 29, 41-49. [CrossRef]

38. Goldman, S.N.; Liss, D.T.; Brown, T.; Lee, J.Y.; Buchanan, D.R.; Balsley, K.; Cesan, A.; Weil, J.; Garrity, B.H.; Baker, D.W. Comparative Effectiveness of Multifaceted Outreach to Initiate Colorectal Cancer Screening in Community Health Centers: A Randomized Controlled Trial. J. Gen. Intern. Med. 2015, 30, 1178-1184. [CrossRef] [PubMed]

39. Gupta, S.; Miller, S.; Koch, M.; Berry, E.; Anderson, P.; Pruitt, S.L.; Borton, E.; Hughes, A.E.; Carter, E.; Hernandez, S.; et al. Financial Incentives for Promoting Colorectal Cancer Screening: A Randomized, Comparative Effectiveness Trial. Am. J. Gastroenterol. 2016, 111, 1630-1636. [CrossRef] 
40. Brenner, A.T.; Rhode, J.; Yang, J.Y.; Baker, D.; Drechsel, R.; Plescia, M.; Reuland, D.S.; Wroth, T.; Wheeler, S.B. Comparative Effectiveness of Mailed Reminders with and Without Fecal Immunochemical Tests for Medicaid Beneficiaries at a Large County Health Department: A Randomized Controlled Trial. Cancer 2018, 124, 3346-3354. [CrossRef] [PubMed]

41. Coronado, G.D.; Petrik, A.F.; Vollmer, W.M.; Taplin, S.H.; Keast, E.M.; Fields, S.; Green, B.B. Effectiveness of a Mailed Colorectal Cancer Screening Outreach Program in Community Health Clinics The STOP CRC Cluster Randomized Clinical Trial. JAMA Intern. Med. 2018, 178, 1174-1181. [CrossRef]

42. Mehta, S.J.; Oyalowo, A.; Reitz, C.; Dean, O.; McAuliffe, T.; Asch, D.A.; Doubeni, C.A. Text messaging and lottery incentive to improve colorectal cancer screening outreach at a community health center: A randomized controlled trial. Prev. Med. Rep. 2020, 19, 101114. [CrossRef] [PubMed]

43. Somsouk, M.; Rachocki, C.; Mannalithara, A.; Garcia, D.; Laleau, V.; Grimes, B.; Issaka, R.B.; Chen, E.; Vittinghoff, E.; Shapiro, J.A.; et al. Effectiveness and cost of organized outreach for colorectal cancer screening: A Randomized Controlled Trial. J. Natl. Cancer Inst. 2020, 112, 30513. [CrossRef] [PubMed]

44. Issaka, R.B.; Avila, P.; Whitaker, E.; Bent, S.; Somsouk, M. Population health interventions to improve colorectal cancer screening by fecal immunochemical tests: A systematic review. Prev. Med. 2019, 118, 113-121. [CrossRef] [PubMed]

45. Rat, C.; Latour, C.; Rousseau, R.; Gaultier, A.; Pogu, C.; Edwards, A.; Nguyen, J.M. Interventions to increase uptake of faecal tests for colorectal cancer screening: A systematic review. Eur. J. Cancer Prev. 2018, 27, 227-236. [CrossRef] [PubMed]

46. Dougherty, M.K.; Brenner, A.T.; Crockett, S.D. Evaluation of Interventions Intended to Increase Colorectal Cancer Screening Rates in the United States: A Systematic Review and Meta-analysis. JAMA Intern. Med. 2018, 178, 1645-1658. [CrossRef]

47. Goodwin, B.C.; Ireland, M.J.; March, S.; Myers, L.; Crawford-Williams, F.; Chambers, S.K.; Aitken, J.F.; Dunn, J. Strategies for increasing participation in mail-out colorectal cancer screening programs: A systematic review and meta-analysis. Syst. Rev. 2019, 8, 257. [CrossRef]

48. Myers, L.; Goodwin, B.; March, S.; Dunn, J. Ways to use interventions to increase participation in mail-out bowel cancer screening: A systematic review and meta-analysis. Transl. Behav. Med. 2019, 10, 384-393. [CrossRef]

49. Vale, D.B.; Anttila, A.; Ponti, A.; Senore, C.; Sankaranaryanan, R.; Ronco, G.; Segnan, N.; Tomatis, M.; Zakelj, M.P.; Elfstrom, K.M.; et al. Invitation strategies and coverage in the population-based cancer screening programmes in the European Union. Eur. J. Cancer Prev. 2019, 28, 131-140. [CrossRef]

50. Basu, P.; Ponti, A.; Anttila, A.; Ronco, G.; Senore, C.; Vale, D.B.; Segnan, N.; Tomatis, M.; Soerjomataram, I.; Primic Zakelj, M.; et al. Status of implementation and organization of cancer screening in The European Union Member States-Summary results from the second European screening report. Int. J. Cancer 2018, 142, 44-56. [CrossRef] [PubMed]

51. Senore, C.; Basu, P.; Anttila, A.; Ponti, A.; Tomatis, M.; Vale, D.B.; Ronco, G.; Soerjomataram, I.; Primic-Zakelj, M.; Riggi, E.; et al. Performance of colorectal cancer screening in the European Union Member States: Data from the second European screening report. Gut 2019, 68, 1232-1244. [CrossRef] [PubMed]

52. Hol, L.; van Leerdam, M.E.; van Ballegooijen, M.; van Vuuren, A.J.; van Dekken, H.; Reijerink, J.C.; van der Togt, A.C.; Habbema, J.D.; Kuipers, E.J. Screening for colorectal cancer: Randomised trial comparing guaiac-based and immunochemical faecal occult blood testing and flexible sigmoidoscopy. Gut 2010, 59, 62-68. [CrossRef] [PubMed]

53. Kapidzic, A.; Grobbee, E.J.; Hol, L.; van Roon, A.H.; van Vuuren, A.J.; Spijker, W.; Izelaar, K.; van Ballegooijen, M.; Kuipers, E.J.; van Leerdam, M.E. Attendance and Yield Over Three Rounds of Population-Based Fecal Immunochemical Test Screening. Am. J. Gastroenterol. 2014, 109, 1257-1264. [CrossRef] [PubMed]

54. Schreuders, E.H.; Grobbee, E.J.; Nieuwenburg, S.A.V.; Kapidzic, A.; van Roon, A.H.C.; van Vuuren, A.J.; Lansdorp-Vogelaar, I.; Spijker, W.W.J.; Izelaar, K.; Bruno, M.J.; et al. Multiple rounds of one sample versus two sample faecal immunochemical test-based colorectal cancer screening: A population-based study. Lancet Gastroenterol. Hepatol. 2019, 4, 622-631. [CrossRef]

55. Toes-Zoutendijk, E.; van Leerdam, M.E.; Dekker, E.; van Hees, F.; Penning, C.; Nagtegaal, I.; van der Meulen, M.P.; van Vuuren, A.J.; Kuipers, E.J.; Bonfrer, J.M.G.; et al. Real-Time Monitoring of Results During First Year of Dutch Colorectal Cancer Screening Program and Optimization by Altering Fecal Immunochemical Test Cut-Off Levels. Gastroenterology 2017, 152, 767-775. [CrossRef] [PubMed]

56. Erasmus MC-NKI/AvL. Montior 2015, National Monitoring of the Colorectal Cancer Screening Programme. 2015. Available online: https:/ / www.rivm.nl/documenten/monitoring-and-evaluation-of-colorectal-cancer-screening-programme-2015 (accessed on 17 May 2020).

57. Erasmus MC-NKI/AvL. Montior 2016, National Monitoring of the Colorectal Cancer Screening Programme. 2016. Available online: https:/ / www.rivm.nl/documenten/monitoring-and-evaluation-of-colorectal-cancer-screening-programme-2016 (accessed on 17 May 2020).

58. Erasmus MC-NKI/AvL. Montior 2017, National Monitoring of the Colorectal Cancer Screening Programme. 2017. Available online: https:/ / www.rivm.nl/sites/default/files/2018-11/DarmMon2017-Engels5.pdf (accessed on 20 January 2020).

59. National Institute for Public Health and the Environment (RIVM) 2019, National Monitoring of the Colorectal Cancer Screening Programme. 2018. Available online: https://iknl.nl/getmedia/35d96a38-d019-4846-b7ac-b000ddff9a1a/2018_Monitordarmkanker_definitief.pdf (accessed on 24 March 2021).

60. Akram, A.; Juang, D.; Bustamante, R.; Liu, L.; Earles, A.; Ho, S.B.; Wang-Rodriguez, J.; Allison, J.E.; Gupta, S. Replacing the Guaiac Fecal Occult Blood Test With the Fecal Immunochemical Test Increases Proportion of Individuals Screened in a Large Healthcare Setting. Clin. Gastroenterol. Hepatol. 2017, 15, 1265-1270. [CrossRef] [PubMed] 